\title{
Differently substituted benzonitriles for non-doped OLEDs
}

\author{
Dalius Gudeika ${ }^{\mathrm{a}, \mathrm{b}}$, Oleksandr Bezvikonnyi ${ }^{\mathrm{a}}$, Dmytro Volyniuk ${ }^{\mathrm{a}}$, Juozas V. Grazulevicius ${ }^{\mathrm{a}, *}$ \\ a Department of Polymer Chemistry and Technology, Kaunas University of Technology, Radvilenu pl. 19, LT-50254, Kaunas, Lithuania \\ ${ }^{\mathrm{b}}$ Institute of Solid State Physics, University of Latvia, Kengaraga st. 8, LV-1063, Riga, Latvia
}

A R T I C L E I N F O

\section{Keywords:}

TADF

Phenoxazine

Phenothiazine

Dimethylacridine

Carbazole

Bipolar charge transport

\begin{abstract}
A B S T R A C T
Towards highly efficient doping-free organic light-emitting diodes, five benzonitrile-based emitters with different substitution pattern were designed exploiting symmetrical donor-acceptor-donor and asymmetrical donoracceptor-donor* structures. As it was predicted by theoretical calculations, different thermally activated delayed fluorescence of different energy with relatively high absolute quantum yields (11-42\%) was detected for nondoped films of the studied compounds. The smallest singlet-triplet energy splitting of $0.05 \mathrm{eV}$ thus the most efficient TADF was estimated for the film of compound with the asymmetrical donor-acceptor-donor* structure containing carbazole and acridan donor moieties. Thermogravimetry revealed sublimation of the materials with the onset temperatures in the range of $350-383^{\circ} \mathrm{C}$. Glass transition temperatures of the molecular materials were in the range of $82-94{ }^{\circ} \mathrm{C}$. Tuning of hole injection properties of these compounds in solid-state was demonstrated. Their ionization potential was in range from 5.8 to $6.0 \mathrm{eV}$. Strong effect of different substitutions was observed on hole mobilities of the layers of compounds. They were found to be in the wide range from $3 \times 10^{-7}$ $\mathrm{cm}^{2} \mathrm{~V}^{-1} \mathrm{~s}^{-1}$ to $1 \times 10^{-4} \mathrm{~cm}^{2} \mathrm{~V}^{-1} \mathrm{~s}^{-1}$. Electron mobility values of the compounds were found to be comparable and ranged from $1.5 \times 10^{-4} \mathrm{~cm}^{2} \mathrm{~V}^{-1} \mathrm{~s}^{-1}$ to $3 \times 10^{-4} \mathrm{~cm}^{2} \mathrm{~V}^{-1} \mathrm{~s}^{-1}$ at electric field of $6.9 \times 10^{5} \mathrm{Vcm}^{-1}$. Reflecting effect of substitution pattern of benzonitrile on electroluminescent properties of OLEDs, maximum external quantum efficiencies in the range from 1.6 to $5 \%$ as well as maximum brightness in the wide range from 1200 to $22600 \mathrm{~cd} / \mathrm{m}^{2}$ were observed for the devices based on the doping-free light-emitting layer.
\end{abstract}

\section{Introduction}

From the point of view of fabrication technology, doping-free organic light-emitting diodes (OLEDs) are more attractive than the doped ones To develop doping-free OLEDs with competitive parameters, the most important issue is the discovery of electroluminescent materials matching a set of requirements including high photoluminescence quantum yield (PLQY), ability to convert all excitons formed under electrical excitation into light, good charge-injecting and charge-transporting properties, satisfactory thermal and electrochemical stability etc. Therefore, many excellent emitters are not applicable in non-doped OLEDs. For example, simple fluorescent materials are not appropriate since they have an upper limit of external quantum efficiency (EQE) of 5-7.5\% since only onequarter of excitons are singlets and the outcoupling efficiency is of $c a$. $20-30 \%$ [1]. In contrast to OLEDs exploiting the simple fluorescent materials, OLEDs based on phosphorescent heavy metal complexes can harvest both singlet $\left(\mathrm{S}_{1}\right)$ and triplet $\left(\mathrm{T}_{1}\right)$ excitons for light emission, providing the opportunity to realize internal electroluminescence (EL) quantum efficiencies of close to $100 \%$ with an EQE of $20-30 \%$ [2]. Although phosphorescent OLEDs currently have large superiority in quantum efficiencies, rarity of phosphorescent metal complexes such as those of iridium and platinum limit their low-cost and long-term mass production. Most of phosphorescent emitters are non-emissive in doping-free layers since triplet-triplet annihilation is not appropriate for non-doped OLEDs [3].

One of the alternatives to phosphorescent emitters is thermally activated delayed fluorescence (TADF) materials that can convert triplets to singlets via reversed intersystem crossing (rISC), which can lead to the exciton utilization efficiency as high as $100 \%$ [4]. The process requires a small triplet-to-singlet energy gap $\left(\Delta \mathrm{E}_{\mathrm{ST}}\right)$ for a fast rISC which is mainly related to the special molecular design. TADF OLEDs have emerged as the third generation organic electroluminescent devices [5]. The design and application of TADF materials for OLEDs have been an active research area in recent years [6]. It is also discovered that some TADF luminophores are characterized additionally by aggregation-induced emission (AIE) effect being highly emissive in solid-state $[7,8]$. Novel electroluminescent materials exhibiting aggregation-induced delayed fluorescence are the best candidates for doping-free electroluminescent devices up to now [9,10]. The further development of TADF/AIE electroluminescent materials may result in fabrication of non-doped OLEDs with better performance than that of the doped ones.

\footnotetext{
* Corresponding author.

E-mail address: juozas.grazulevicius@ktu.lt (J.V. Grazulevicius).
} 

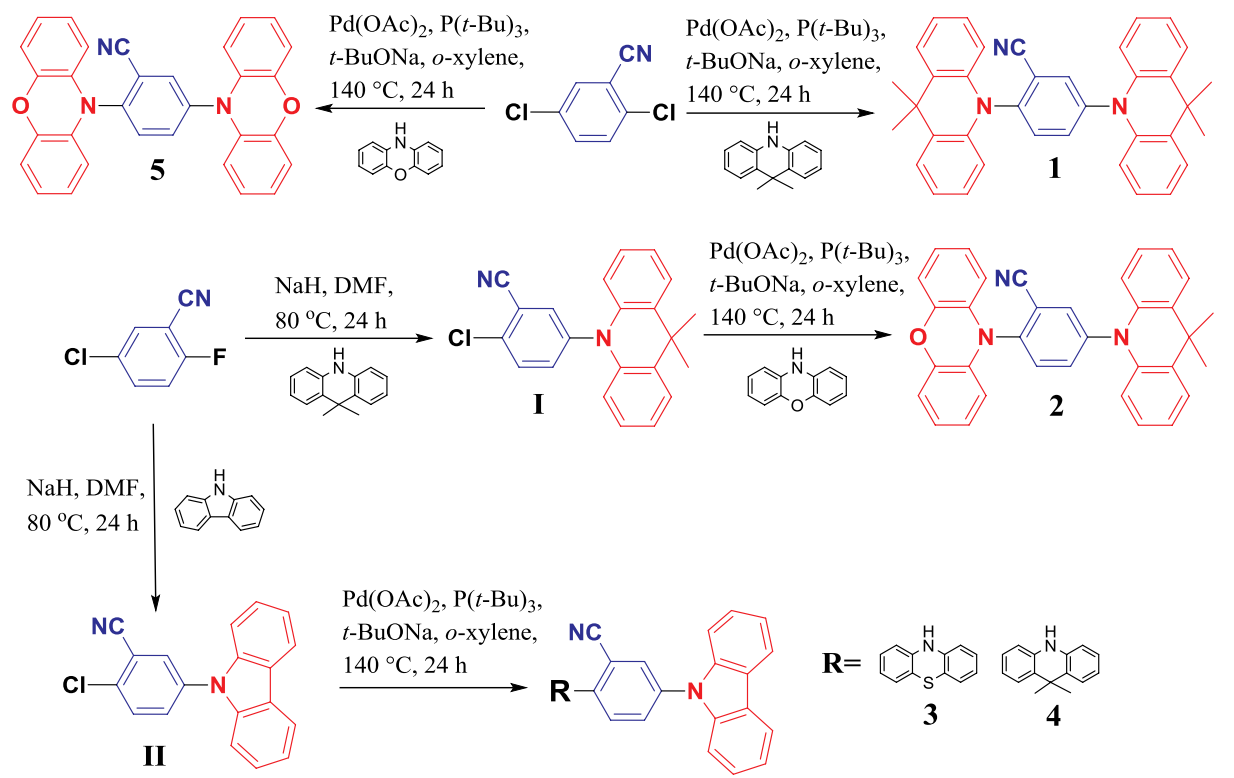

Scheme 1. Synthetic routes to 1-5.

Molecular design of a TADF emitters requires both donor (D) and acceptor (A) functional groups that can create a small spatial overlap between the highest occupied molecular orbital (HOMO) and lowest unoccupied molecular orbital (LUMO), which results in small $\Delta \mathrm{E}_{\mathrm{ST}}$ [11]. Molecular design of a AIE emitters requires some freedom in rotations/vibrations of the chromophores [12,13], while, restriction of the rotations/vibrations in solid-state dramatically increases emission intensity [14].

Various heterocycles, such as phenoxazine, phenothiazine, dimethylacridine and carbazole were used as donor moieties and cyano, sulfone, triazine, xanthone, benzophenone, carbonyl moieties were employed as acceptor units to develop TADF emitters with different emission profiles [6,15-23]. Rational molecular design of derivatives containing electron-accepting cyano-substituted moieties and electrondonating fragments results in TADF emitters [24]. Cyanobenzene moiety containing single cyano group in the conjugated phenyl ring show reduced electron withdrawing strength and weaker intermolecular charge transfer interaction in donor-acceptor (D-A) type derivatives [24]. Compared to dicyano-substituted moieties, monocyano-substituted moieties were less employed for the design of TADF emitters. TADF materials with electron accepting cyanobenzene and electron donating phenoxazine moieties were recently reported [25]. OLEDs containing the layers of these emitters showed EQE up to $19.9 \%$. Emission tuning of TADF emitters based on phenoxazine and triphenyltriazine was realized by changing the number of donor substituents [26]. Study of derivatives of acridan and different $\mathrm{CN}$-containing donors including benzonitrile revealed that TADF emission wavelengths were tunable from deep blue to yellow not only by acceptor strength but also by the control of acceptor conformation (twist angles) [27]. There is still a challenge to develop methods for fine regulation on the emission of the TADF/AIE emitters.

To further develop methods for TADF and AIE emission tuning, in this work, we designed and synthesized five emitters using cyano substituted phenyl moiety as acceptor and carbazole, phenothiazine, phenoxazine, 9,9-dimethyl-9,10-dihydroacridine moieties as donors. It should be noted that many TADF materials with symmetrical D-A-D structures were previously reported [28,29]. Some of such materials have donor units used this work [30,31]. However, asymmetrical benzonitrile derivatives of D-A-D* (D1-A-D2) type were rarely investigated despite the expected positive impact of such material design strategy not only on TADF properties but also on their energy levels, charge drift mobility, thermal and chemical stability etc. For instance, it may be predicted that intramolecular charge transfer between perpendicularly twisted D1 and A units may result in efficient TADF; while, efficient hopping of holes between HOMO-HOMO energy levels of D2 units of neighboring molecules may result in high hole mobility of TADF materials. In this work, the design strategy of TADF materials is mainly related to the development of asymmetrical D-A-D* type cyanobenze derivatives. Availability of efficient asymmetrical TADF emitters can stimulate the further progress in development of non-doped single-layer OLEDs. To initially estimate efficiency of the material design strategy of asymmetrical TADF emitters, detailed evaluation of photophysical, thermal, electrochemical properties and of performance in non-doped OLEDs of the synthesized materials was carried out.work will initiate developing of asymmetrical TADF emitters the best of which will be appropriate for non-doped onelayered OLEDs. To initially express efficiency of the material design strategy of asymmetrical TADF emitters, detailed evaluation of photophysical, thermal, electrochemical properties and of performance in nondoped OLEDs of the synthesized materials was carried out.

\section{Results and discussion}

\subsection{Synthesis and characterization}

The synthetic route for compounds $\mathbf{1 - 5}$ is depicted in Scheme 1. First, the intermediate compound I was synthesized by the palladiumcatalyzed Buchwald-Hartwig coupling reaction between 2,5-dichlorobenzonitrile and 9,9-dimethyl-9,10-dihydroacridine. Another intermediate compound II was prepared via nucleophilic cross-coupling reaction between $9 \mathrm{H}$-carbazole and 2-bromo-5-fluorobenzonitrile. Target compounds 1-5 were prepared under the similar reaction conditions as I, using compounds I, II and commercially available 2,5-dichlorobenzonitrile, $10 \mathrm{H}$-phenothiazine, $10 \mathrm{H}$-phenoxazine, 9,9-dimethyl-9,10-dihydroacridine. All the compounds were purified by adsorption chromatography and fully characterized using ${ }^{1} \mathrm{H}$ NMR and ${ }^{13} \mathrm{C}$ NMR spectroscopy, mass spectrometry and elemental analysis.

\subsection{Theoretical calculations}

To understand the structure-property relationship of compounds 1-5 at the molecular level, the geometrical and electronic properties of the compounds were studied using density functional theory (DFT) and time-dependent DFT (TDDFT) calculations with the B3LYP hybrid functional. 


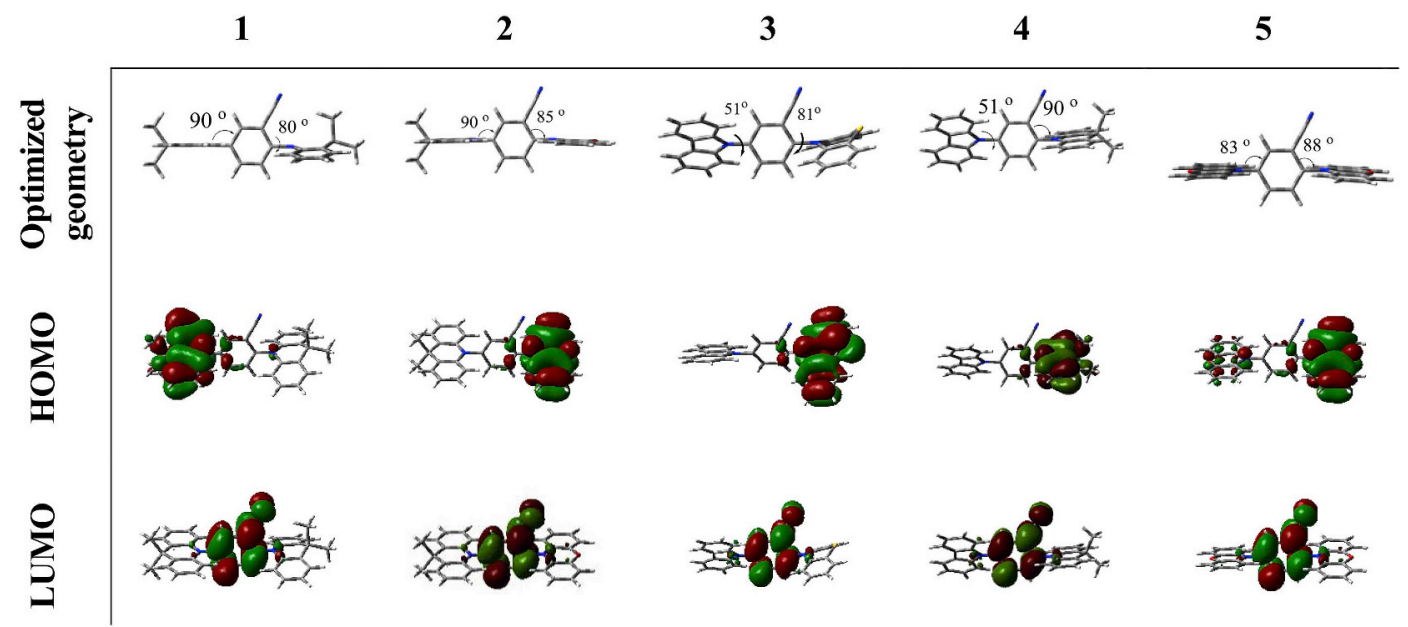

Fig. 1. Optimized geometries and molecular orbital plots (B3LYP/6-31G (d,p)) of compounds 1-5 in gas phase.

Fig. 1 shows optimized molecular structures of the compounds having highly twisted structures with dihedral angles between the electron-donating and electron-accepting moieties ranging from 51 to $90^{\circ}$. The twisted structures of compounds 1-5 lead to spatially separated frontier orbital distributions with the highest occupied molecular orbitals (HOMOs) being mainly localized on the donor (carbazolyl, acridanyl, phenoxazinyl and phenothiazinyl) moieties and the lowest unoccupied molecular orbitals (LUMOs) centered on the acceptor (cyanobenzene) moieties. The HOMO energy levels of the compounds 1-5 were calculated to be $-5.21,-4.92,-5.12,-5.16$ and $-4.96 \mathrm{eV}$ while the LUMO were $-1.83,-1.92,-1.82,-1.84$ and $-1.99 \mathrm{eV}$, respectively.

To evaluate the values of singlet-triplet gap $\left(\Delta \mathrm{E}_{\mathrm{ST}}\right)$, the triplet and the singlet energies were theoretically calculated based on the molecule ground state geometry with triplet energies of $2.68,2.27,2.62,2.54$ and $2.24 \mathrm{eV}$, and singlet energies of 2.72, 2.29, 2.63, 2.56 and $2.26 \mathrm{eV}$ for 1, 2, 3, 4 and 5, respectively. Apparently, the twisted structures of 1-5 are responsible for small singlet-triplet energy splittings ranging from 0.01 to $0.04 \mathrm{eV}$.

\subsection{Thermal properties}

The behavior under heating of compounds $\mathbf{1 - 5}$ was studied by DSC and TGA under a nitrogen atmosphere. The data are collected in Table 1. It was found that all of the derivatives demonstrated relatively high thermal stability. The temperatures of decomposition onsets $\left(\mathrm{T}_{\mathrm{d}}\right)$ were in the range of $350-383^{\circ} \mathrm{C}$ (Fig. S2).

All the compounds 1-5 were obtained as crystalline materials after the synthesis as confirmed by DSC. However they could be converted into amorphous materials by cooling the melted samples. DSC thermograms of $\mathbf{4}$ are shown in Fig. 2. When the crystalline sample was heated during the DSC experiment, an endothermic peak due to melting $\left(\mathrm{T}_{\mathrm{m}}\right)$ was observed at $218^{\circ} \mathrm{C}$. When the melt sample was cooled down,

Table 1

Thermal characteristics of compounds 1-5.

\begin{tabular}{llll}
\hline Compound & $\mathrm{T}_{\mathrm{m}},\left[{ }^{\circ} \mathrm{C}\right]^{\mathrm{a}}$ & $\mathrm{T}_{\mathrm{g}},\left[{ }^{\circ} \mathrm{C}\right]^{\mathrm{b}}$ (2nd heating scan) & $\mathrm{T}_{\mathrm{d}},\left[{ }^{\circ} \mathrm{C}\right]^{\mathrm{c}}$ \\
\hline $\mathbf{1}$ & 284 & 94 & 371 \\
$\mathbf{2}$ & 255 & 83 & 370 \\
$\mathbf{3}$ & 232 & 86 & 383 \\
$\mathbf{4}$ & 218 & 88 & 367 \\
$\mathbf{5}$ & 226 & 82 & 350
\end{tabular}

${ }^{\text {a }} \mathrm{T}_{\mathrm{m}}$ is melting temperature at the scan rate of $10^{\circ} \mathrm{C} / \mathrm{min}, \mathrm{N}_{2}$ atmosphere.

b $T_{g}$ is glass-transition temperature.

${ }^{c} \mathrm{~T}_{\mathrm{d}}$ is the temperature of the onset of thermal degradation recorded at the scan rate of $20^{\circ} \mathrm{C} / \mathrm{min}, \mathrm{N}_{2}$ atmosphere.

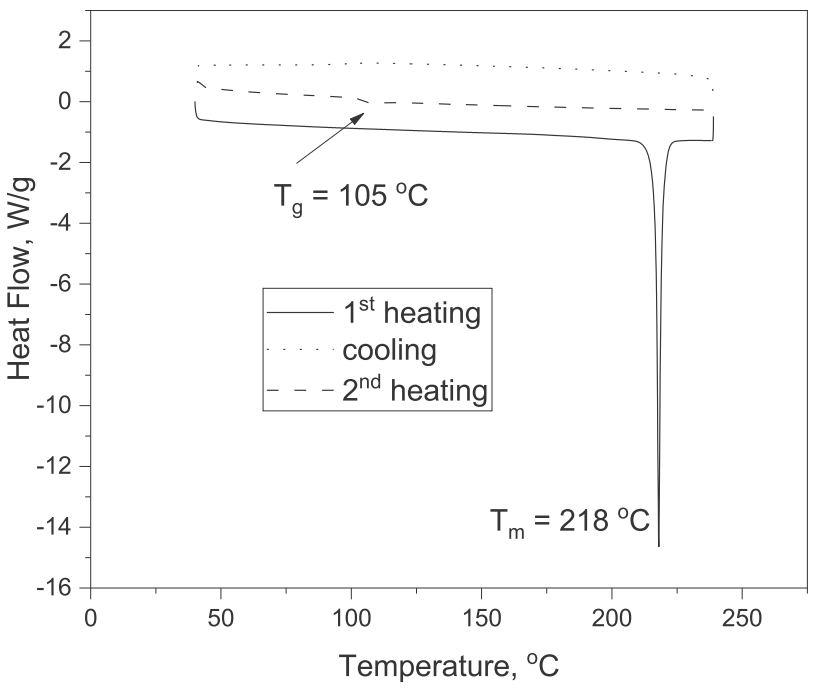

Fig. 2. DSC thermograms of compound 4.

its glass transition temperature $\left(\mathrm{T}_{\mathrm{g}}\right)$ was observed at $88^{\circ} \mathrm{C}$. Compounds 1-3 and 5 demonstrated the analogous behaviour during the DSC tests (Table 1). The temperatures of thermal transitions of the derivatives (1-5) were found similar and did not depend considerably on their chemical structures.

\subsection{Photophysical properties}

To understand impact of substitution pattern of benzonitrile-based emitters on their photophysical properties, the electronic absorption and photoluminescence (PL) spectra of the solid films and dilute solutions were recorded (Fig. 3). Major photophysical data are collected in Table 2. The solutions of compounds $\mathbf{1 - 5}$ in toluene displayed quite different absorption profiles because of the different donor substituents. The similarity was observed between the vibronic-structured low-energy bands in the range of $290-355 \mathrm{~nm}$ of absorption spectra of the solutions of compounds 3 and 4 containing carbazole moieties. The effect of other donor moieties, i.e., phenothiazine or 9,9-dimethyl-9,10dihydroacridine was practically not detectable in the low-energy bands of absorption spectra of the solutions of asymmetric compounds $\mathbf{3}$ and 4. The similar absorption spectra were also observed for the solutions in THF and for the films of compounds 3 and 4 (Fig. 3a). For toluene solutions of compounds $\mathbf{1}$ and $\mathbf{2}$, only absorption tails of the compounds were observed because of absorption of the solvent (up to $300 \mathrm{~nm}$ ). 


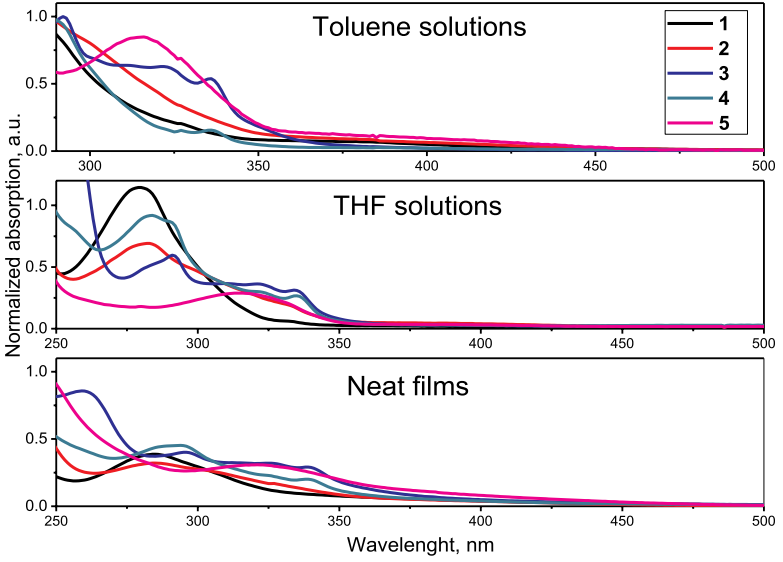

a)

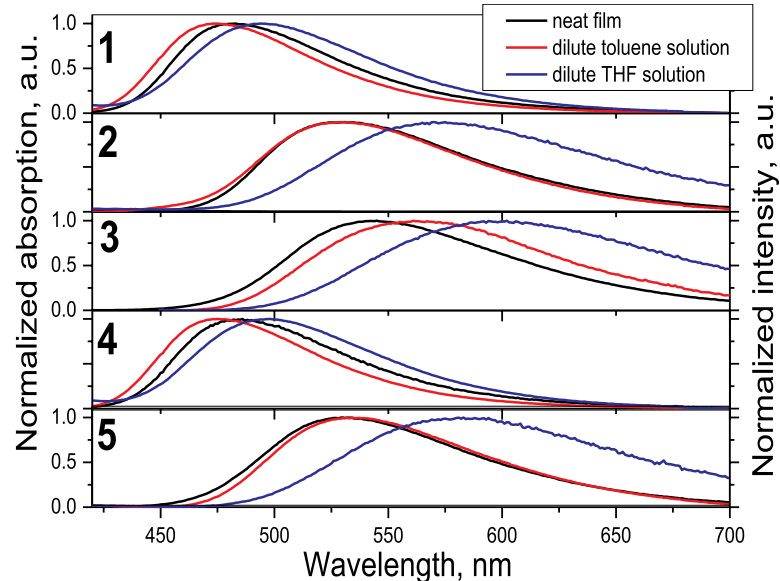

b)

Fig. 3. UV-vis (a) and PL (b) spectra of neat films, dilute toluene and THF solutions of compounds 1-5.

Absorption spectra of the solutions in THF of compounds $\mathbf{1}$ and $\mathbf{2}$ showed well-observed band peaking at $281 \mathrm{~nm}$. This band is mainly related to 9,9-dimethyl-9,10-dihydroacridine moiety. The shoulder at $316 \mathrm{~nm}$ related to absorption of phenoxazine moiety can be recognized in absorption spectrum of the solution of compound 2. Absorption spectra of the solution of compound $\mathbf{5}$ were characterized by well-observed band peaking at $316 \mathrm{~nm}$ which is apparently also related to the phenoxazine moiety. In UV spectra of toluene solutions and of the films of all the synthesized compounds, weak absorption tails extending to near $430-460 \mathrm{~nm}$ can be recognized. These tails are apparently related to the charge transfer (CT) between the donors and accepting benzonitrile unit. Solvatochromic effect for absorption spectra of the solutions of compounds 1-5 was not detected. Practically no differences in UV spectra of toluene solutions, THF solutions and solid films of the same compound were detected. Theoretical and experimental absorption spectra of the compounds are in good agreement (Fig. S1). The theoretical results indicate the presence of the several excited sates of charge transfer (CT) nature exhibiting practically zero oscillator strength with negligible conjugation as it was observed for compounds exhibiting TADF [32].

Displaying effect of substitution pattern of benzonitrile-based emitters on their emission properties, the single emission peaks in the relatively wide range of ca. $470-560 \mathrm{~nm}$ were observed in PL spectra of the toluene solutions of compounds $\mathbf{1 - 5}$ at room temperature. Different donating abilities of the attached donors resulted in the different intramolecular interactions between donating and accepting units, thus determining the fluorescent characteristics (Fig. 3b, Table 2). PL spectra in blue/sky-blue region were observed for the solutions of compounds 1 and 4 . These derivatives have similar structures except the replacement of one acridan moiety by carbazole unit in compound 4 . It can be concluded that spectral characteristics of these compounds and their PLQY values are completely determined by dimethylacridine moiety and the weaker carbazole donor unit does not have any substantial impact on emissive properties of compound 4. Similarly, the photophysical properties of phenoxazine-containing compounds $\mathbf{2}$ and $\mathbf{5}$ are almost identical regardless of the presence of 9,9-dimethyl-9,10-dihydroacridine unit in the structure of 2 . However, dimethylacridine moiety is, apparently, responsible for slightly higher PLQY of the films of $\mathbf{2}$ in comparison to that of the film of 5 (cf. 26 and 18\%, respectively). Comparison of the photophysical properties of $\mathbf{1}$ and $\mathbf{2}$ revealed that the presence of phenoxazine moiety in compound $\mathbf{2}$, which stronger donor than 9,9-dimethyl-9,10-dihydroacridine revealed the shift of PL peak of compound 2 into green spectral range and decrease of PLQY of the compound dispersed in non-polar medium. Yellow emission of $\mathbf{3}$ is the least efficient and the most spectrally red-shifted among emissions of the series which is obviously not because of the presence of carbazole moiety in the structure of 3. Phenoxazine moiety, which is the strongest donor used in the investigation, has the major effect on emissive properties of 3 . Consequently, the stronger donor predetermines photophysical properties of the studied assymetrical D-A-D* type compounds. PL spectra in blue/sky-blue region were observed for the solutions of compounds 1 and 4 containing either 9,9-dimethyl-9,10-dihydroacridine or carbazole

Table 2

Photophysical parameters derived from steady state and time resolved spectroscopic measurements of dilute THF, toluene solutions and thin films of compounds performed at $77 \mathrm{~K}$ and at room temperature.

\begin{tabular}{|c|c|c|c|c|c|c|c|c|c|c|}
\hline Compound & $\lambda, \mathrm{nm}^{\mathrm{a}}$ & $\Phi_{\mathrm{PL}} \mathrm{THF}^{\mathrm{b}}$ & $\Phi_{\mathrm{PL}} \mathrm{Tol}^{\mathrm{b}}$ & $\Phi_{\mathrm{PL}}$ film $^{\mathrm{c}}$ & $\mathrm{E}_{\mathrm{S} 1}{ }^{\mathrm{d}}, \mathrm{eV}$ & $\mathrm{E}_{\mathrm{T} 1}{ }^{\mathrm{d}}, \mathrm{eV}$ & $\Delta \mathrm{E}_{\mathrm{ST}}{ }^{\mathrm{d}}, \mathrm{eV}$ & Ratio dg/air ${ }^{\mathrm{f}}$ & Ratio, DF/PF ${ }^{g}$ & slope $^{\mathrm{h}}$ \\
\hline 1 & 482 & 0.11 & 0.13 & 0.42 & $2.91(2.72)$ & $2.80(2.68)$ & $0.11(0.04)$ & 1.6 & 0.65 & 1.0 \\
\hline 2 & 529 & 0.03 & 0.13 & 0.26 & $2.74(2.29)$ & $2.62(2.27)$ & $0.12(0.02)$ & 3.5 & 0.96 & 1.0 \\
\hline 3 & 543 & 0.01 & 0.04 & 0.11 & $2.71(2.63)$ & $2.52(2.62)$ & $0.19(0.01)$ & 2.4 & 0.88 & 0.92 \\
\hline 4 & 483 & 0.12 & 0.14 & 0.39 & $2.89(2.56)$ & $2.84(2.54)$ & $0.05(0.02)$ & 3.0 & 3.80 & 0.92 \\
\hline 5 & 530 & 0.03 & 0.12 & 0.18 & $3.21^{\mathrm{e}}(2.26)$ & $3.10^{\mathrm{e}}(2.24)$ & $0.11^{\mathrm{e}}(0.02)$ & 2.8 & - & - \\
\hline
\end{tabular}

a Wavelength of the PL peak of the neat films of compounds.

b PLQY of deoxygenated THF solutions. PLQY of deoxygenated toluene solutions.

c PLQY of the neat films.

d Estimated from the emission spectra of the neat films at $77 \mathrm{~K}$.

e Estimated from the emission spectra of dilute THF solutions recorded at $77 \mathrm{~K}$ (Fig. S3).

${ }^{\mathrm{f}}$ The ratio of PL intensities of degassed and air equilibrated toluene solutions recorded at $293 \mathrm{~K}$.

$\mathrm{g}$ The ratio of DF and PF yields of the neat films estimated from the time resolved spectroscopic measurements at $293 \mathrm{~K}$.

$\mathrm{h}$ The slopes of linear fit of the log-log DF integral intensity dependence on the excitation power at all range of applied power at $293 \mathrm{~K}$. The theoretical values of $\mathrm{E}_{\mathrm{S} 1}, \mathrm{E}_{\mathrm{T} 1}$ and $\Delta \mathrm{E}_{\mathrm{ST}}$ are presented in parentheses. 


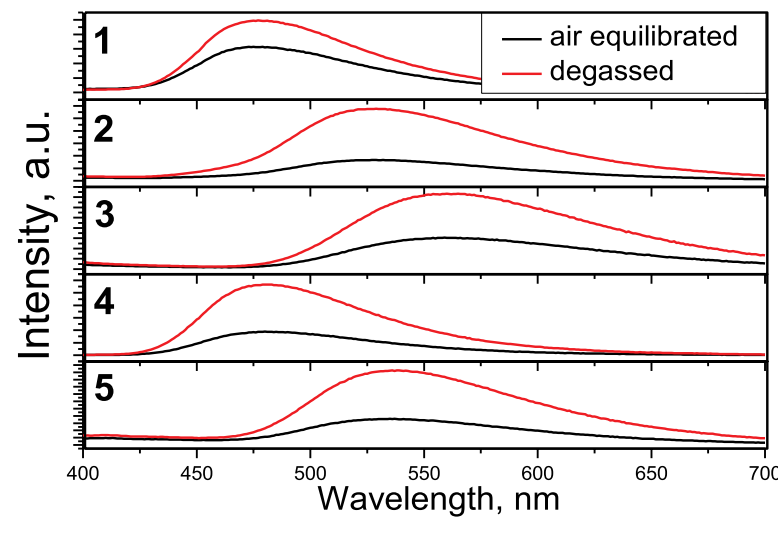

a)

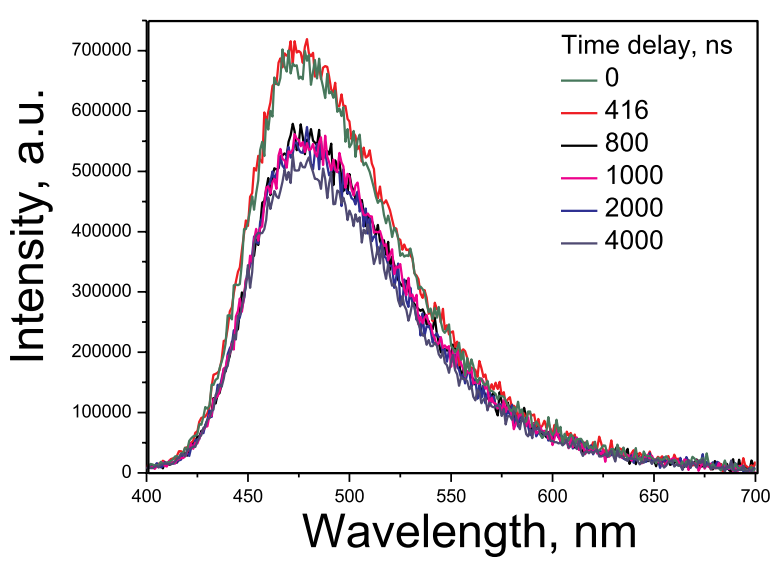

b)

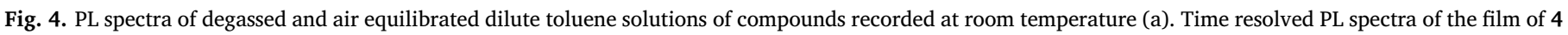
recorded at room temperature (b).

moieties. PL spectra of the solutions of compounds 2, 3 and $\mathbf{5}$ in toluene were red-shifted to green/yellow regions because of the presence of phenothiazine and/or phenoxazine substituents. Different donating abilities of the attached donors resulted in different intramolecular interactions between donor and accepting units, thus determining the color of emission. PL spectra of corresponding THF solutions were red-shifted with respect of the spectra of the solutions of the corresponding donors and acceptor. This observation indicates intramolecular CT which was widely observed for emitters containing donor and acceptor moieties $[6,33]$. PL intensities of THF solutions of the compounds were found to be very sensitive to oxygen (Fig. 4a). This observation can be related to the triplet harvesting and converting into light via TADF. The nature of triplet harvesting will be discussed below. The deoxygenated toluene solutions were characterized by relatively weak emission Their absolute PLQYs did not exceed 14\%. Measured in air, PLQYs of the films of the studied compounds were found to be much higher than those of the dilute solutions and reached $42 \%$. The comparison of PLQY values of the solid films and of dilute solutions allows to conclude that aggregation induced emission enhancement (AIEE) is characteristic of compounds 1-5 (Table 2) [34]. Interestingly, PL spectra of the films of the studied compounds were found in the similar range or even were blue-shifted in comparison to PL spectra of the corresponding toluene solutions (Fig. 3b). On the one hand, it may be assumed that dielectric constants of the compounds 1-5 are similar to the dielectric constant of toluene and, therefore, emissions were observed in the same ranges. On the other hand, aggregation can induce not only emission intensity enhancement but also blue-shifts of PL spectra as it was reported elsewhere [35].

For neat films of the studied series of experiments was done to confirm the existence of TADF. DF was detected for the solid films at room temperature under inert atmosphere. The spectra of prompt and delayed fluorescence are given in Figs. 4b and S5. DF quantum yields were found to be relatively high in comparison with those of PF. The ratios of intensities of PF and DF of the films correlate well with the ratios emission intensities of air equilibrated and degassed THF solutions (Table 2, Figs. 4 and S5). Both the ratios reflect the contribution of triplet excitons in radiative process.

In donor-acceptor-donor molecules near-orthogonal geometry minimizes singlet-triplet energy splitting between first singlet and triplet excited state energy levels making TADF possible [36]. Energy splitting lower than $0.2 \mathrm{eV}$ enables to predict TADF as the probable cause of DF. Energy levels of the singlet and triplet excited states were estimated from onsets of the emission spectra of the neat films recorded at $77 \mathrm{~K}$ under inert atmosphere. (Table 2, Figs. 5b and S6). The triplet levels $\left(\mathrm{E}_{\mathrm{T} 1}\right)$ of the studied compounds evaluated both theoretically and experimentally were found to be dependent on the triplet levels of the donors. The presence of phenoxazine donor significantly decreased the triplet energy values of compounds 2 and 5 to $c a$. $2.6 \mathrm{eV}$. Correspondingly, the values of $\mathrm{E}_{\mathrm{T} 1}$ of $\mathbf{1}$ and $\mathbf{4}$ containing dimethylacridine moiety were found to be higher than $2.8 \mathrm{eV}$. The lowest $\mathrm{E}_{\mathrm{T} 1}$ of $2.52 \mathrm{eV}$ was observed for the film of $\mathbf{3}$, containing phenothiazine moiety, which is the strongest donor used in the studied series. Thermal activation of the $\mathrm{DF}$, was detected after heating up the solid samples to the temperatures higher than $180 \mathrm{~K}$ by analysis of PL decay curves (Figs. 5c and S7). This observation confirms that the origin of DF is TADF. The slopes of $0.92-1$ of linear fits of the log-log DF integral intensity dependences on the excitation power at all the range of applied power measured at room temperature is additional evidence of TADF nature of DF (Table 2, Figs. 5d and S8). Spectral characteristics of the compounds are described in more detail in Supporting Information.

\subsection{Electrochemical and photoelectrical properties}

Electrochemical properties of derivatives 1-5 were investigated by cyclic voltammetry (CV). Compounds $\mathbf{1}, 4$ and 5 exhibited quasireversible oxidation peaks at $\sim 0.6 \mathrm{~V}$, while 2 and 3 showed quasireversible oxidation peaks at $\sim 0.3 \mathrm{~V}$ (Figs. $6 \mathrm{a}$ and S10). These signals can be attributed to the oxidation of appropriate donors. All the compounds 1-5 showed similar irreversible reduction potentials of ca. $-2.40--2.50 \mathrm{~V}$, which can be attributed to the reduction of cyanobenzene moiety. Thus, it can be concluded, that compounds $\mathbf{2}$ and $\mathbf{3}$ are oxidized easier than compounds 1, 4 and 5. Consequently, slightly lower ionization potential ( $\mathrm{IP}_{\mathrm{CV}}$ ) values were observed for compounds 2 and 3 (5.10 and $5.11 \mathrm{eV}$, respectively) relative to those of compounds $\mathbf{1}$, 4 and 5 (5.39, 5.37 and $5.46 \mathrm{eV}$, respectively). The estimated electron affinity $\left(\mathrm{EA}_{\mathrm{CV}}\right)$ values for compounds $\mathbf{1 - 5}$ were found to be in the range of 2.28-2.49 eV (see Table 3).

Additionally, the solid samples of compounds 1-5 were tested by photoelectron emission spectroscopy in air. Ionization potential ( $\mathrm{IP}_{\mathrm{EP}}$ ) values of the films were found to be in the range from 5.83 to $6.0 \mathrm{eV}$ (Fig. 6b).

\subsection{Charge transporting properties}

Owing donor-acceptor structure of the synthesized compounds, bipolar charge carrier transport was expected. To study the impact of donor substituents on charge-transporting properties of vacuum-deposited films, TOF measurements we performed generating holes or electrons on the ITO/film interface by optical excitation through the 


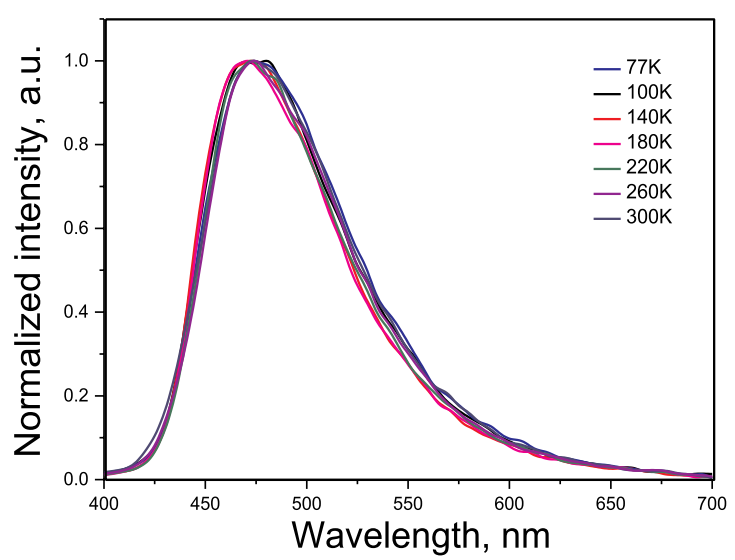

a)

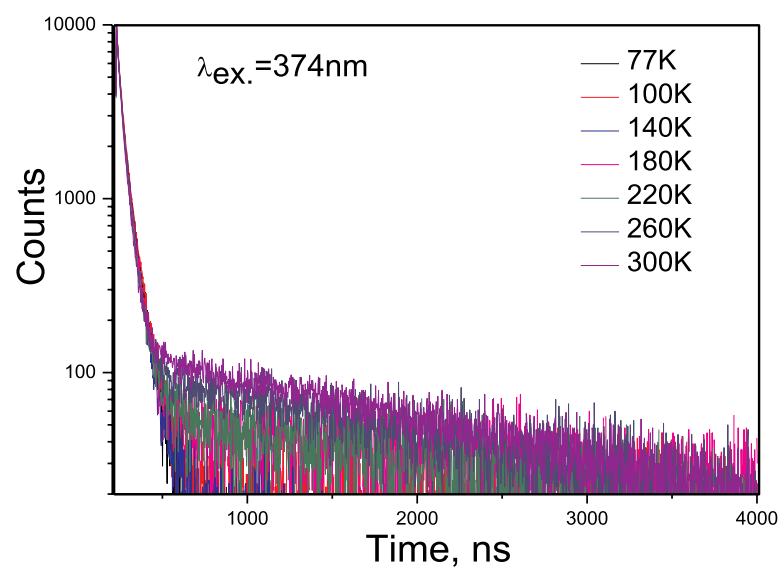

c)

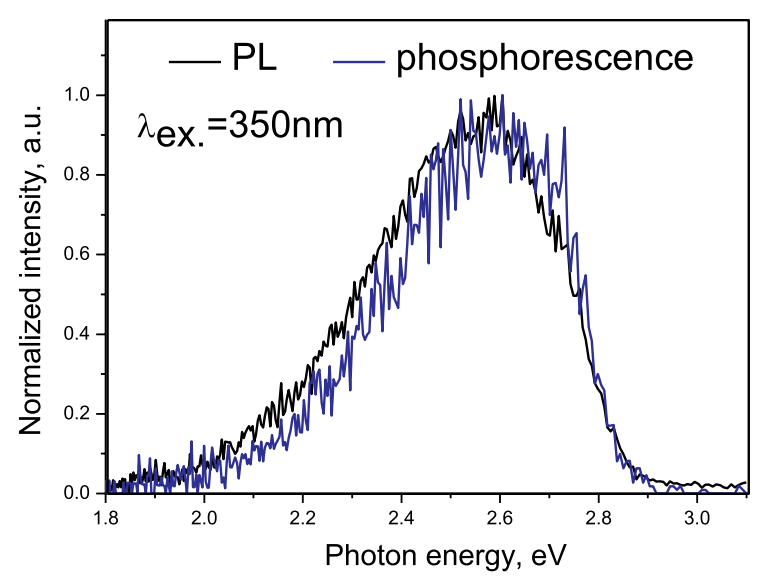

b)

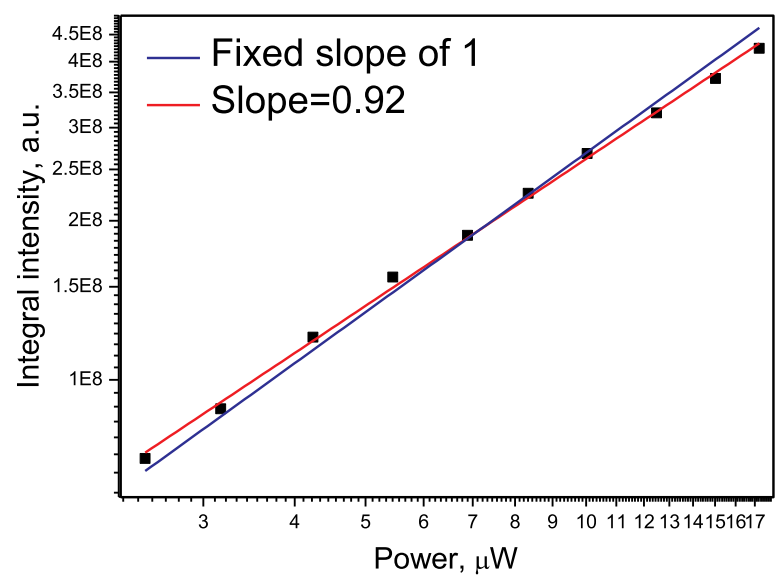

d)

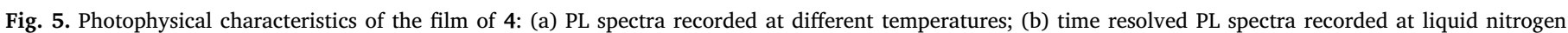

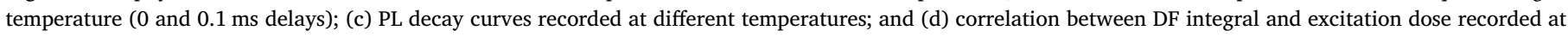
room temperature.

Table 3

Redox potentials, electron affinities, ionization potentials and HOMO/LUMO energies of compounds $\mathbf{1 - 5}$.

\begin{tabular}{|c|c|c|c|c|}
\hline Compound & $\begin{array}{l}\mathrm{E}_{\text {onset }}^{\text {ox }} \text { vs Fc, } \\
{[\mathrm{V}]}\end{array}$ & $\begin{array}{l}\mathrm{E}_{\text {onset }}^{\mathrm{red}} \mathrm{a} \mathrm{Vs} \text { Fc, } \\
{[\mathrm{V}]}\end{array}$ & $\begin{array}{l}\mathrm{IP}_{\mathrm{CV}}^{\mathrm{b}} / \mathrm{HOMO}^{\mathrm{c}} \\
{[\mathrm{eV}]}\end{array}$ & $\begin{array}{l}\mathrm{EA}_{\mathrm{CV}}{ }^{\mathrm{b}} / \mathrm{LUMO}^{\mathrm{c}} \\
{[\mathrm{eV}]}\end{array}$ \\
\hline 1 & 0.59 & -2.38 & $5.39 /-5.21$ & $2.39 /-1.83$ \\
\hline 2 & 0.30 & -2.40 & $5.10 /-4.92$ & $2.39 /-1.92$ \\
\hline 3 & 0.31 & -2.36 & $5.11 /-5.12$ & $2.44 /-1.82$ \\
\hline 4 & 0.57 & -2.47 & $5.37 /-5.16$ & $2.49 /-1.84$ \\
\hline 5 & 0.66 & -2.34 & $5.46 /-4.96$ & $2.28 /-1.99$ \\
\hline
\end{tabular}

${ }^{\mathrm{a}} \mathrm{E}_{\text {onset }}^{\text {ox }}$ and $\mathrm{E}_{\text {onset }}^{\text {red }}$ were measured $v s$. ferrocene/ferrocenium.

b Calculated with reference to ferrocene $(4.8 \mathrm{eV})$. Ionization potentials and electron affinities estimated according to $\mathrm{IP}_{\mathrm{CV}}=\left(\mathrm{E}_{\text {onset }}^{\text {ox }}+4.8\right) \quad[\mathrm{eV}]$. $\mathrm{E} A_{C V}=-\left(\mathrm{E}_{\text {onset }}^{\text {red }}+4.8\right)[\mathrm{eV}]$ (where, $\mathrm{E}_{\text {onset }}^{\text {red }}$ and $\mathrm{E}_{\text {onset }}^{\text {ox }}$ are the onset reduction and oxidation potentials versus the $\mathrm{Fc} / \mathrm{Fc}^{+}$).

c Estimated HOMO/LUMO levels.

ITO electrode using a pulsed laser $(\lambda=355 \mathrm{~nm})$ and different polarity of applied voltages (positive on ITO for holes and negative for electrons). Thus, the photogenerated either holes or electrons were transported through the layer from ITO electrode to the opposite $\mathrm{Al} \mathrm{elec-}$ trode under different external electric fields. Because of very dispersive charge transport, the transit times $\left(t_{\mathrm{tr}}\right)$ for holes and electrons at different applied electric fields were taken from the corresponding photocurrent transients in log-log scales (Fig. 7). Having $t_{\text {tr }}$ and thicknesses of the tested films, hole $\left(\mu_{\mathrm{h}}\right)$ and electron $\left(\mu_{\mathrm{e}}\right)$ mobilities were calculated using equation $\mu_{\mathrm{h}}\left(\mu_{\mathrm{e}}\right)=d^{2} /\left(\mathrm{U} \times t^{\mathrm{tr}}\right)$. As it is widely accepted, charge drift mobility versus electric fields (E) is presented according to the Poole-Frenkel relationship $\mu=\alpha_{0} \mathrm{e}^{\alpha \mathrm{E}^{1 / 2}}$, where $\alpha$ is the field dependence parameter [37] (Fig. 7c).

Hole mobilities of the layers of the studied compounds ranged from $3 \times 10^{-7} \mathrm{~cm}^{2} \mathrm{~V}^{-1} \mathrm{~s}^{-1}$ to $1 \times 10^{-4} \mathrm{~cm}^{2} \mathrm{~V}^{-1} \mathrm{~s}^{-1}$ displaying strong effect of donor substituents on hole transporting properties of the studied compounds. Hole mobilities increased in the order $4>5>$ $1>2>3$. The highest hole mobilities were observed for compounds 4 and 5 containing carbazole/acridan or phenoxazine units, respectively. The lowest hole mobility was observed for compound 3 containing carbazole and phenothiazine donor moieties. Since the same accepting unit was used, comparable electron mobility values were recorded for compounds 1-5. They ranged from ca. $1.5 \times 10^{-4}$ $\mathrm{cm}^{2} \mathrm{~V}^{-1} \mathrm{~s}^{-1}$ to $3 \times 10^{-4} \mathrm{~cm}^{2} \mathrm{~V}^{-1} \mathrm{~s}^{-1}$ at electric field of $6.9 \times 10^{5}$ $\mathrm{Vcm}^{-1}$. Slight differences were apparently determined by different molecular packing of the molecules in solid-state. 


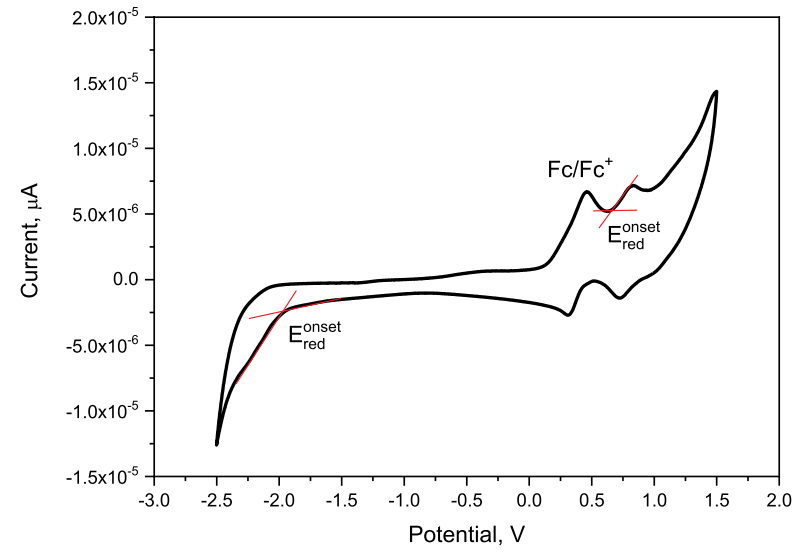

a)

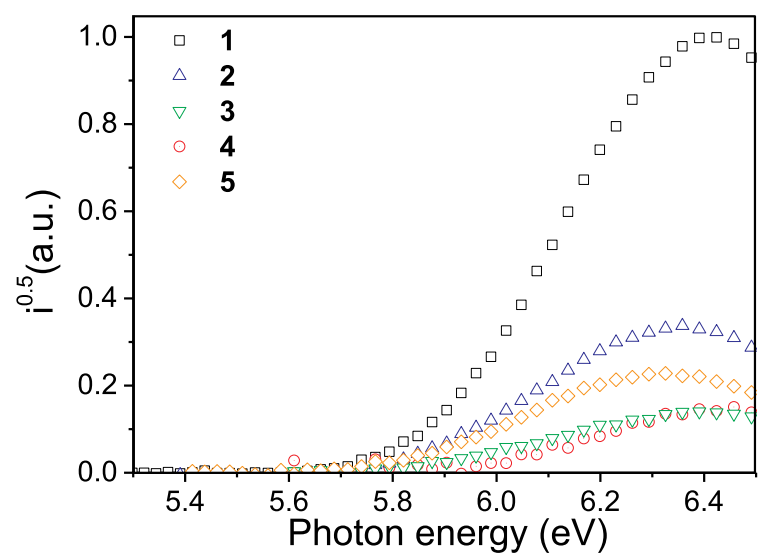

b)

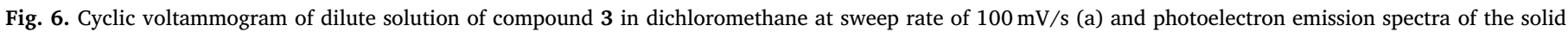
samples of compounds 1-5 (b).

\subsection{Device fabrication and characterization}

Taking into account relatively high PLQY values reaching $42 \%$ of the neat films, bipolar charge transport, and relatively good charge-transporting properties of compounds $\mathbf{1 - 5}$, they can be regarded as promising candidates for doping-free OLEDs. To gain insight into the electroluminescent characteristics of the studied compounds, they were used as TADF emitters in non-doped OLEDs with structures $\mathrm{ITO} / \mathrm{MoO}_{3} / \mathrm{NPB} /$ non-doped light-emitting layer/TSPO1/TPBi/LiF/Al (Fig. 8). Non-doped light-emitting layers of these devices (named as 1A-5A) were prepared from compounds $\mathbf{1 - 5}$, respectively. $\mathrm{MoO}_{3}$ as the hole injection layer, $N, N^{\prime}$-di(1-naphthyl)- $N, N^{\prime}$-diphenyl-(1,1'-biphenyl)-4,4'-diamine (NPB) as the hole transport layer, diphenyl-4-triphenylsilylphenyl-phosphine oxide (TSPO1) as the hole/exciton blocking layer, 2,2',2"-(1,3,5-benzinetriyl)-tris(1-phenyl-1- $H$-benzimidazole) (TPBi) as the electron transporting layer, and LiF as the electron injection layer were employed. Fig. 8 shows the structure and energy diagrams of devices 1A-5A.

Major electroluminescent parameters of the fabricated OLEDs are listed in Table 4. Current density-voltage-luminance (J-V-L) characteristics, current efficiency, power efficiency and EQE versus current density curves as well as the EL spectra are presented in Fig. 9. The similar EL spectra of devices 1A-5A were obtained at different applied voltages proving that the recombination of hole-electron pairs occurred within the light-emitting layers. In addition, EL spectra of devices 1A-5A were in good agreement with PL spectra of the films for the studied emitters. EL

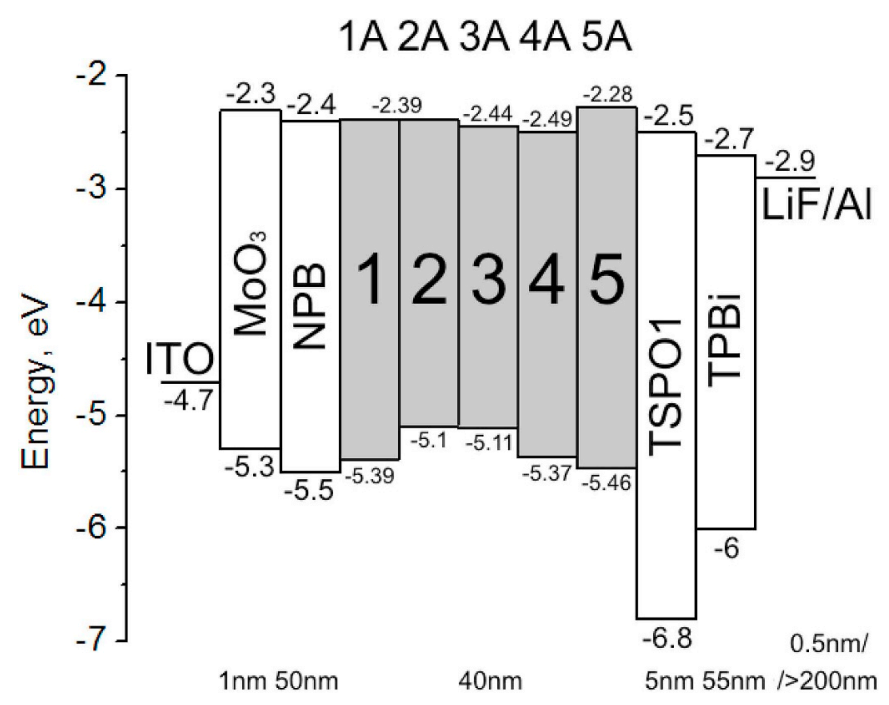

Fig. 8. Energy diagram of the studied non-doped OLEDs with a light-emitting layers of 1-5.

spectra of devices 1A and 4A containing emitters with 9,9-dimethyl9,10-dihydroacridine or carbazole moieties were blue shifted in comparison to those of the devices based on emitters $\mathbf{2}, \mathbf{3}$ and $\mathbf{5}$ (Fig. 9c). CIE

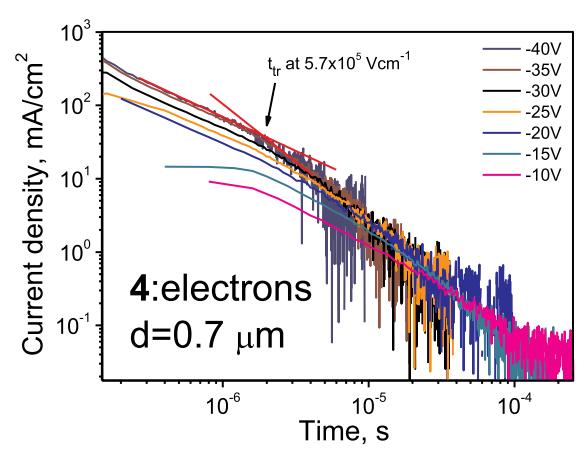

a)

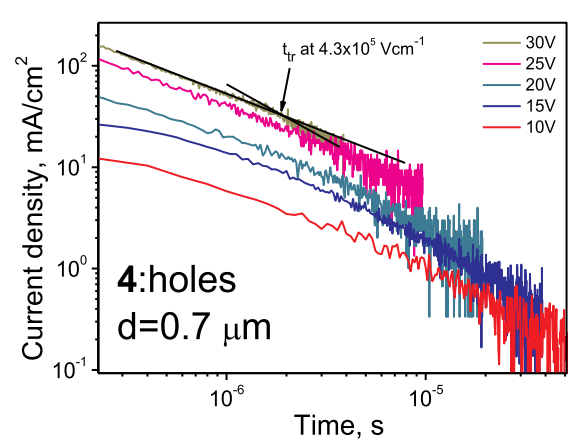

b)

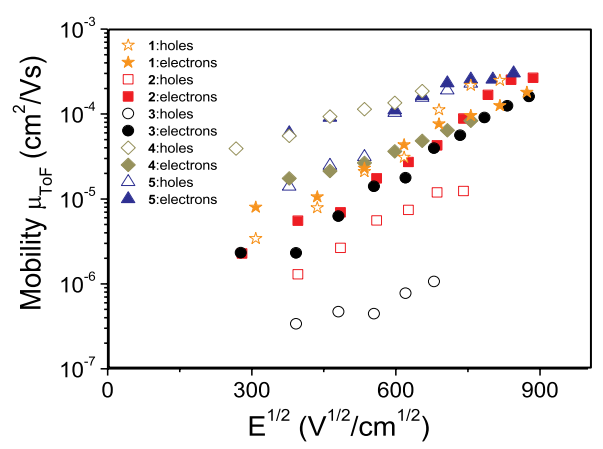

c)

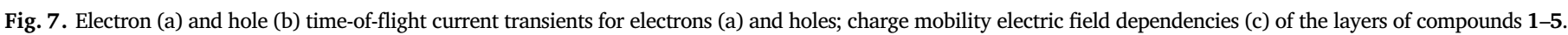


Table 4

Electroluminescence parameters of OLEDs.

\begin{tabular}{|c|c|c|c|c|c|c|c|}
\hline Device & $\mathrm{EML}^{\mathrm{a}}$ & $\mathrm{L}_{\max }, \times 10^{3} \mathrm{~cd} / \mathrm{m}^{2 \mathrm{~b}}$ & $\mathrm{~V}_{\mathrm{on}}, \mathrm{V}^{\mathrm{c}}$ & $\eta_{c}, c d / A^{d}$ & $\eta_{\mathrm{p}}, \operatorname{lm} / \mathrm{W}^{\mathrm{e}}$ & $\mathrm{EQE}, \%^{\mathrm{f}}$ & $\mathrm{CIE}^{\mathrm{g}}$ \\
\hline 1A & 1 & 5.3 & 3.6 & $5.3(4.8)$ & $3.6(3.6)$ & $2.5(2.2)$ & $\left(\begin{array}{l}0.187 \\
0.285\end{array}\right)$ \\
\hline $2 A$ & 2 & 22.6 & 3.4 & $16.3(11.5)$ & $12.2(10.0)$ & $5.0(3.5)$ & $(0.3090 .565)$ \\
\hline $3 A$ & 3 & 1.2 & 4.4 & $5.2(4.0)$ & $3.5(2.4)$ & $1.6(1.3)$ & $\left(\begin{array}{lll}0.347 & 0.522)\end{array}\right.$ \\
\hline $4 \mathrm{~A}$ & 4 & 2.6 & 4.5 & $8.4(7.7)$ & $4.9(4.6)$ & $4.1(3.7)$ & $\left(\begin{array}{lll}0.181 & 0.271\end{array}\right)$ \\
\hline $5 A$ & 5 & 10.4 & 3.6 & 7.7 (6.9) & $6.0(5.6)$ & $2.4(2.1)$ & $\left(\begin{array}{lll}0.337 & 0.555)\end{array}\right.$ \\
\hline
\end{tabular}

a Type of EML.

b Maximum brightness.

c Turn-on voltage.

d Maximum current efficiency.

e Maximum power efficiency.

f Maximum external quantum efficiency.

g CIE 1931 UCS coordinates at $8 \mathrm{~V}$. The values in parentheses are presented at $100 \mathrm{~cd} / \mathrm{m}^{2}$.

1931 UCS coordinates represent color (blue-yellow range) of electroluminescence of the developed doping-free devices (Table 4). Blue OLEDs were obtained using emitters 1 and 4 based on 9,9-dimethyl-9,10dihydroacridine or carbazole moieties.

Efficient injection of charge carriers from electrodes and following transport to emitting layer is evidenced by the low turn-on voltages of all fabricated OLEDs (3.3-4.5 V). The highest values of maximum EQEs among devices 1A-5A were obtained for devices based on TADF emitters 2 and 4 having asymmetrical structures with 9,9-dimethyl-9,10-dihydroacridine and either phenoxazine or carbazole moieties (5 and 4.1\%, respectively). Despite the highest PLQY value observed for film of $\mathbf{1}$, OLEDs based on compound 1 showed maximum EQE of only $2.5 \%$, apparently, because of the smaller contribution of TADF in its emission (DF/PF intensity ratio of 0.65 ) (Table 2). The lowest maximum EQE value of $1.6 \%$ was obtained for device $3 \mathrm{~A}$ based on the compound 3 containing carbazole and phenothiazine donors most probably was due to both the lowest PLQY value and the lowest hole mobilities of the films of the compound. The best device 2A showed maximum current efficiency of $16.3 \mathrm{~cd} / \mathrm{A}$, maximum power efficiency of $12.2 \mathrm{~lm} / \mathrm{W}$ and maximum EQE of $5 \%$ (Table 4). The maximum brightness of $22600 \mathrm{~cd} /$ $\mathrm{m}^{2}$ was also obtained for device $2 \mathrm{~A}$. The highest brightness of this device can partly be explained by the position of its electroluminescence spectrum which was in the range of maximum sensitivity of human eyes. The analysis of the obtained results for non-doped devices 1A-5A shows that $\mathrm{EQE}$ values are below the theoretically calculated ones. The theoretical values estimated by the formula EQEs $=\left(\gamma \times \eta_{\mathrm{ST}} \times\right.$ PLQY $) \times \eta_{\text {out }}$ were found to be $8.4-12.6 \%$ for the device based on $1,5.2-7.8 \%$ for the device based on $2,2.2-3.3 \%$ for the device containing $3,7.8-11.7 \%$ for the device containing 4 and $3.6-6.5 \%$ for the device based on 5 taking PLQYs of the emitters (Table 2), the best charge balance factor $\gamma=1$, the fraction of radiative excitons $\eta_{\mathrm{ST}}=1$ as it is for TADF emitters, and the outcoupling efficiency $\eta_{\text {out }}=0.2$ or 0.3 , respectively. Since the calculated EQE values were higher than the experimental ones, it was clear that the structures of devices $1 \mathrm{~A}-\mathbf{5 A}$ did not meet the requirements for the best charge balance factor $(\gamma=1)$. Therefore, electroluminescent properties of the selected compounds 1, 2 and 4 were additionally tested in OLEDs using structure ITO/HAT-CN/TCTA/mCP/non-doped lightemitting layer/TSPO1/TPBi/LiF/Al of devices which were designated as 1A1, 2A1 and 4A1, respectively. In these devices, improvement of the charge balance in light-emitting layers was expected, thus improving of $\gamma$, using the layers of hexaazatriphenylenehexacarbonitrile (HAT-CN), tris(4-carbazoyl-9-ylphenyl)amine (TCTA), and 1,3-bis( $N$-carbazolyl) benzene (mCP) as hole-injection, hole-transporting and exciton-blocking layers, respectively. Indeed, higher maximum EQEs of 3.4 and $6.2 \%$ were observed for devices 1A1 and 2A1 in comparison to maximum EQEs of 2.5 and $5 \%$ of devices $\mathbf{1 A}$ and $\mathbf{2 A}$ based on the same emitters, respectively (Figs. S11 and S1). Meanwhile, device 4A1 showed lower maximum EQE than device 4A. Apparently, the structure of this device is not appropriate for the best charge balance in light-emitting of compound 4 .
Despite lower PLQY (26\%) of compound 2 relative to those of compounds 1 and 4, (42 and 39\%) experimental EQEs of devices $2 \mathrm{~A}$ and $2 \mathrm{~A} 1$ were higher than those of devices $1 \mathrm{~A}, 1 \mathrm{A1}, 4 \mathrm{~A}$ and $4 \mathrm{A1}$. In addition, the experimental EQEs of doping-free devices 2A and 2A1 well correlated with the theoretical value $(5.2-7.8 \%)$. The highest charge balance factor $\gamma$ was obtained for devices 2A and 2A1 being mainly responsible for the highest device performance.

Doping for emitting layers of OLEDs based on AIEE emitters 1-5 did not lead to any impressive improvement of the characteristics. For example, doping of emitter 2 resulted in luminance drop from 22600 to $14900 \mathrm{~cd} / \mathrm{m}^{2}$ and slight increase of turn-on voltage. In addition, it also resulted in the increase of OLED efficiency to $21.2 \mathrm{~cd} / \mathrm{A}, 15.7 \mathrm{~lm} / \mathrm{W}$ and EQE of $7.3 \%$ apparently because of the improvement of charge-transporting properties. More information and discussions on EL characteristics of doped devices are given in Supporting Information.

We believe that our research of emissive properties of the variety of newly synthesized derivatives influenced by specific donor substitution will be helpful in a field of a molecular design of D-A-D and D-A-D* TADF emitters for highly efficient electroluminescent devices.

In addition, the electroluminescent properties of the synthesized differently substituted benzonitriles in with those of reported benzonitrile-based TADF materials were compared (Table S2).

\section{Conclusions}

In this work, we report on the synthesis properties and performance in doping-free OLEDs of five donor-acceptor-donor derivatives containing cyanobenzene acceptor moiety and carbazole, phenothiazine, phenoxazine, 9,9-dimethyl-9,10-dihydroacridine donor units utilizing symmetrical doror-acceptop-donor and asymmetrical structures dororacceptop-donor*. Effects of different donor substitutions on photophysical, thermal, electrochemical, electrooptical, and electroluminescent properties of the newly synthesized compounds were studied. The HOMO/LUMO separation for the enhancement of a reverse intersystem crossing was achieved by unsymmetrical donor substitution of cyanobenzene moiety resulting in efficient thermally-activated delayed fluorescence with absolute quantum yield of solid non-doped samples reaching $42 \%$. Emission color of the compounds was sensitive to the substitution pattern. It ranged from blue (for carbazole/acridancontaining compounds) to green (for phenothiazine/phenoxazine-containing compounds). The compounds were characterized by bipolar charge transport with different hole mobility values (up to $1 \times 10^{-4}$ $\mathrm{cm}^{2} \mathrm{~V}^{-1} \mathrm{~s}^{-1}$ at electric field of $6.9 \times 10^{5} \mathrm{Vcm}^{-1}$ ) and with close electron mobility values (up to $3 \times 10^{-4} \mathrm{~cm}^{2} \mathrm{~V}^{-1} \mathrm{~s}^{-1}$ at electric field of $6.9 \times 10^{5} \mathrm{Vcm}^{-1}$ ). The synthesized compounds showed good performances in doping-free OLEDs. The device based on phenoxazine and acridan containing benzonitrile derivative showed maximum current efficiency of $16.3 \mathrm{~cd} / \mathrm{A}$, maximum power efficiency of $12.2 \mathrm{~lm} / \mathrm{W}$ and maximum external quantum efficiency of $5 \%$. 


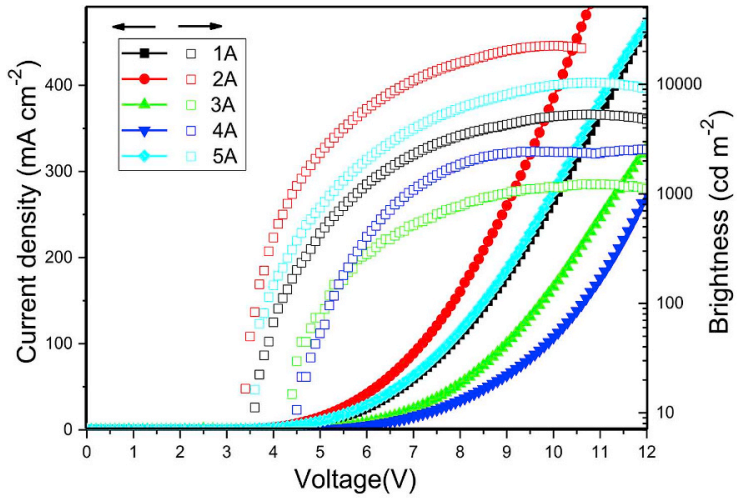

a)

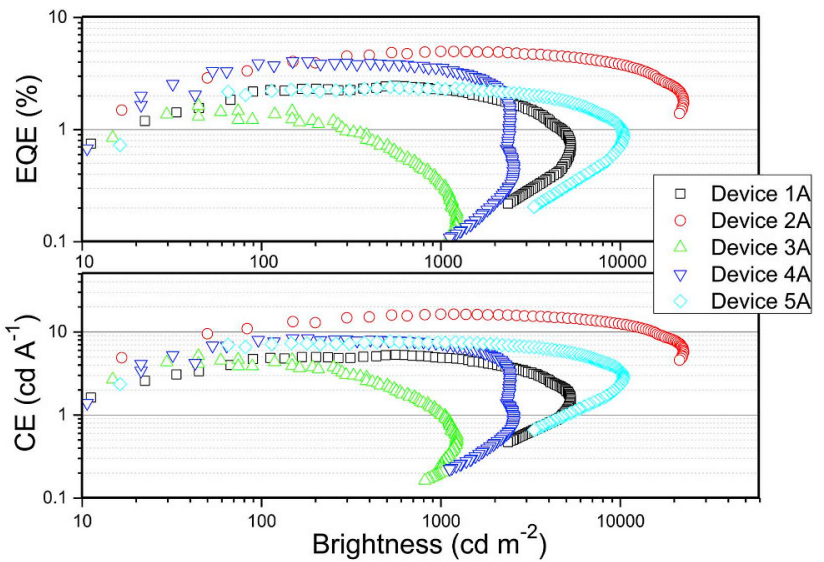

b)

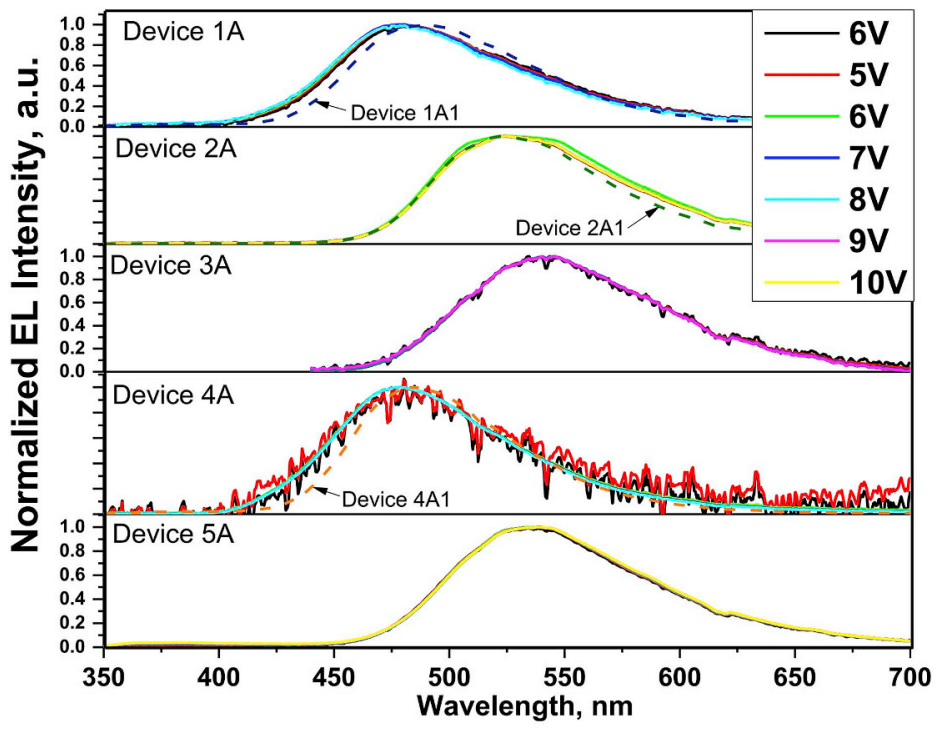

c)

Fig. 9. Electroluminescent properties of OLEDs 1A-5A: volte-current density and volte-luminance (a), EQE, current efficiency-current density (b) characteristics and EL spectra (c) of investigated non-doped OLEDs. Dashed curves indicate EL spectra at $10 \mathrm{~V}$.

\section{Acknowledgements}

DG acknowledges to the ERDF PostDoc grant No. 1.1.1.2/VIAA/1/ 16/177. This research was funded by the European Regional Development Fund according to the supported activity 'Research Projects Implemented by World-class Researcher Groups' under Measure No. 01.2.2-LMT-K-718.

\section{Appendix A. Supplementary data}

Supplementary data to this article can be found online at https:// doi.org/10.1016/j.dyepig.2019.107789.

\section{References}

[1] Wu TL, Huang MJ, Lin CC, Huang PY, Chou TY, Chen-Cheng RW, et al. Diboron compound-based organic light-emitting diodes with high efficiency and reduced efficiency roll-off. Nat Photonics 2018;12:235-40. https://doi.org/10.1038/ s41566-018-0112-9.

[2] Chu-Yun K, Wei-Lung T, Bihai T, Min J, Wei-Kai L, Yun C, et al. Bis-tridentate Ir(III) complexes with nearly unitary RGB phosphorescence and organic light-emitting diodes with external quantum efficiency exceeding 31\%. Adv Mater 2016;28:2795-800. https://doi.org/10.1002/adma.201505790.

[3] Wei Q, Fei N, Islam A, Lei T, Hong L, Peng R, et al. Small-molecule emitters with high quantum efficiency: mechanisms, structures, and applications in OLED devices. Adv Opt Mater 2018;6:1800512 1-31. https://doi.org/10.1002/adom.201800512.

[4] Jankus V, Data P, Graves D, McGuinness C, Santos J, Bryce MR, et al. Highly efficient TADF OLEDs: how the emitter-host interaction controls both the excited state species and electrical properties of the devices to achieve near $100 \%$ triplet harvesting and high efficiency. Adv Funct Mater 2014;24:6178-86. https://doi.org/10 1002/adfm. 201400948.

[5] Yokoyama D, Endo A, Adachi C, Ogasawara M, Takahashi A, Kato Y. Thermally activated delayed fluorescence from $\mathrm{Sn} 4+$-porphyrin complexes and their application to organic light emitting diodes - a novel mechanism for electroluminescence. Adv Mater 2009;21:4802-6. https://doi.org/10.1002/adma. 200900983.

[6] (a) Uoyama H, Goushi K, Shizu K, Nomura H, Adachi C. Highly efficient organic light-emitting diodes from delayed fluorescence. Nature 2012;492:234-8. https:// doi.org/10.1038/nature11687;

(b) Tao Y, Yuan K, Chen T, Xu P, Li H, Chen R, et al. Thermally activated delayed fluorescence materials towards the breakthrough of organoelectronics. Adv Mater 2014;26:7931-58. https://doi.org/10.1002/adma.201402532.

[7] Guo J, Zhao Z, Tang BZ. Purely organic materials with aggregation-induced delayed fluorescence for efficient nondoped OLEDs. Adv Opt Mater 2018;6:1800264 1-11. https://doi.org/10.1002/adom.201800264.

[8] Li Q, Li Z. The strong light-emission materials in the aggregated state: what happens 
from a single molecule to the collective group. Adv Sci 2017;4:1600484 1-15. https://doi.org/10.1002/advs.201600484.

[9] Rizzo F, Cucinotta F. Recent developments in AIEgens for non-doped and TADF OLEDs. Isr J Chem 2018;58:874-88. https://doi.org/10.1002/ijch.201800049.

[10] Zeng J, Guo J, Liu H, Lam JWY, Zhao Z, Chen S, et al. Aggregation-induced delayed fluorescence luminogens for efficient organic light-emitting diodes. Chem Asian J 2019;14:828-35. https://doi.org/10.1002/asia.201801588.

[11] Zeng W, Lai HY, Lee WK, Jiao M, Shiu YJ, Zhong C, et al. Achieving nearly $30 \%$ external quantum efficiency for orange-red organic light emitting diodes by employing thermally activated delayed fluorescence emitters composed of 1,8-naph thalimide-acridine hybrids. Adv Mater 2018;30:1704961 1-8. https://doi.org/10. 1002/adma.201704961.

[12] Mei J, Leung NLC, Kwok RTK, Lam JWY, Tang BZ. Aggregation-induced emission: together we shine, united we soar!. Chem Rev 2015;115:11718-940. https://doi. org/10.1021/acs.chemrev.5b00263.

[13] Hong Y, Lam JWY, Tang BZ. Aggregation-induced emission: phenomenon, mechanism and applications. Chem Commun 2009:4332-53. https://doi.org/10. 1039/b904665h.

[14] Chen Y, Lam JWY, Kwok RTK, Liu B, Tang BZ. Aggregation-induced emission: fundamental understanding and future developments. Mater Horizons 2019;6:428-33. https://doi.org/10.1039/c8mh01331d.

[15] Zhang Q, Li B, Huang S, Nomura H, Tanaka H, Adachi C. Efficient blue organic light-emitting diodes employing thermally activated delayed fluorescence. Nat Photonics 2014;8:326-32. https://doi.org/10.1038/nphoton.2014.12.

[16] Tanaka H, Shizu K, Miyazaki H, Adachi C. Efficient green thermally activated de layed fluorescence (TADF) from a phenoxazine-triphenyltriazine (PXZ-TRZ) derivative. Chem Commun 2012;48:11392-4. https://doi.org/10.1039/c2cc36237f.

[17] Liu W, Zheng CJ, Wang K, Chen Z, Chen DY, Li F, et al. Novel carbazol-pyridinecarbonitrile derivative as excellent blue thermally activated delayed fluorescence emitter for highly efficient organic light-emitting devices. ACS Appl Mater Interfaces 2015;7:18930-6. https://doi.org/10.1021/acsami.5b05648.

[18] Zhang D, Duan L, Zhang D, Qiao J, Dong G, Wang L, et al. Extremely low driving voltage electrophosphorescent green organic light-emitting diodes based on a host material with small singlet-triplet exchange energy without p- or n-doping layer. Org Electron Physics, Mater Appl 2013;14:260-6. https://doi.org/10.1016/j.orgel. 2012.11.003.

[19] Sato K, Shizu K, Yoshimura K, Kawada A, Miyazaki H, Adachi C. Organic luminescent molecule with energetically equivalent singlet and triplet excited states for organic light-emitting diodes. Phys Rev Lett 2013;110:247401-5. https://doi.org/ 10.1103/PhysRevLett.110.247401.

[20] Zhang Q, Li J, Shizu K, Huang S, Hirata S, Miyazaki H, et al. Design of efficient thermally activated delayed fluorescence materials for pure blue organic light emitting diodes. J Am Chem Soc 2012;134:14706-9. https://doi.org/10.1021/ ja306538w.

[21] Lee SY, Yasuda T, Yang YS, Zhang Q, Adachi C. Luminous butterflies: efficient exciton harvesting by benzophenone derivatives for full-color delayed fluorescence OLEDs. Angew Chem Int Ed 2014;53:6402-6. https://doi.org/10.1002/anie. 201402992.

[22] Zhang Y, Zhang D, Cai M, Li Y, Zhang D, Qiu Y, et al. Towards highly efficient red thermally activated delayed fluorescence materials by the control of intra-molecular $\pi-\pi$ Stacking interactions. Nanotechnology 2016;27:1-8. https://doi.org/10 1088/0957-4484/27/9/094001.

[23] Wang Z, Li Y, Cai X, Chen D, Xie G, Liu KK, et al. Structure-performance investigation of thioxanthone derivatives for developing color tunable highly efficient thermally activated delayed fluorescence emitters. ACS Appl Mater Interfaces
2016;8:8627-36. https://doi.org/10.1021/acsami.5b12559.

[24] Cao X, Zhang D, Zhang S, Tao Y, Huang W. CN-Containing donor-acceptor-type small-molecule materials for thermally activated delayed fluorescence OLEDs. J Mater Chem C 2017;5:7699-714. https://doi.org/10.1039/c7tc02481a.

[25] Chen DY, Liu W, Zheng CJ, Wang K, Li F, Tao SL, et al. Isomeric thermally activated delayed fluorescence emitters for color purity-improved emission in organic lightemitting devices. ACS Appl Mater Interfaces 2016;8:16791-8. https://doi.org/10. 1021/acsami.6b03954.

[26] Tanaka H, Shizu K, Nakanotani H, Adachi C. Twisted intramolecular charge transfer state for long-wavelength thermally activated delayed fluorescence. Chem Mater 2013;25:3766-71. https://doi.org/10.1021/cm402428a.

[27] Pan KC, Li SW, Ho YY, Shiu YJ, Tsai WL, Jiao M, et al. Efficient and tunable thermally activated delayed fluorescence emitters having orientation-adjustable $\mathrm{CN}$-substituted pyridine and pyrimidine acceptor units. Adv Funct Mater 2016;26:7560-71. https://doi.org/10.1002/adfm.201602501.

[28] Wong MY, Zysman-Colman E. Purely organic thermally activated delayed fluorescence materials for organic light-emitting diodes. Adv Mater 2017;29:1605444 1-54. https://doi.org/10.1002/adma.201605444.

[29] Braveenth R, Lee H, Kim S, Raagulan K, Kim S, Kwon JH, et al. High efficiency green TADF emitters of acridine donor and triazine acceptor D-A-D structures. J Mater Chem C 2019;7:7672-80. https://doi.org/10.1039/c9tc02491c.

[30] Im Y, Kim M, Cho YJ, Seo J-A, Yook KS, Lee JY. Molecular design strategy of organic thermally activated delayed fluorescence emitters. Chem Mater 2017;29:1946-63. https://doi.org/10.1021/acs.chemmater.6b05324.

[31] Bezvikonnyi O, Gudeika D, Volyniuk D, Mimaite V, Sebastine BR, Grazulevicius JV. Effect of donor substituents on thermally activated delayed fluorescence of diphenylsulfone derivatives. J Lumin 2019;206:250-9. https://doi.org/10.1016/j.jlumin. 2018.10.018.

[32] Zeng W, Gong S, Zhong C, Yang C. Prediction of oscillator strength and transition dipole moments with the nuclear ensemble approach for thermally activated delayed fluorescence emitters. J Phys Chem C 2019;123:10081-6. https://doi.org/10. 1021/acs.jpcc.9b02376.

[33] Ma F, Cheng Y, Zheng Y, Ji H, Hasrat K, Qi Z. Rational design of thermally activated delayed fluorescence emitters with aggregation-induced emission employing combined charge transfer pathways for fabricating efficient non-doped OLEDs. J Mater Chem C 2019(7):9413-22. https://doi.org/10.1039/C9TC02467K.

[34] Sych G, Simokaitiene J, Bezvikonnyi O, Tsiko U, Volyniuk D, Gudeika D, et al. Exciplex-enhanced singlet emission efficiency of nondoped organic light emitting diodes based on derivatives of tetrafluorophenylcarbazole and tri/tetraphenylethylene exhibiting aggregation-induced emission enhancement. J Phys Chem C 2018;122:14827-37. https://doi.org/10.1021/acs.jpcc.8b03895.

[35] Yang X, Lu R, Zhou H, Xue P, Wang F, Chen P, et al. Aggregation-induced blue shift of fluorescence emission due to suppression of TICT in a phenothiazine-based organogel. J Colloid Interface Sci 2009;339:527-32. https://doi.org/10.1016/j.jcis. 2009.07.033.

[36] (a) Santos PL, Ward JS, Data P, Batsanov AS, Bryce MR, Dias FB, et al. Engineering the singlet-triplet energy splitting in a TADF molecule. J Mater Chem C 2016;4:3815-24. https://doi.org/10.1039/c5tc03849a;

(b) Dias FB, Santos J, Graves DR, Data P, Nobuyasu RS, Fox MA, et al. The role of local triplet excited states and D-A relative orientation in thermally activated delayed fluorescence: photophysics and devices. Adv Sci 2016;3:1600080-9. https://doi.org/10.1002/advs.201600080.

[37] Arkhipov VI. Fishchuk II, Kadashchuk A, Bassler H. In: Lanzani G, editor. Photophysics of molecular materials. Weinheim: WileyVCH Verlag GmbH \& Co. KGaA; 2006. p. 350-6. Ch. 6.

Institute of Solid State Physics, University of Latvia as the Center of Excellence has received funding from the European Union's Horizon 2020 Framework Programme H2020-WIDESPREAD-01-2016-2017TeamingPhase2 under grant agreement No. 739508, project CAMART2 